unfortunate if the political pressure to push legislation through did not allow the time needed to create a law that is fit for purpose. The rushed proposal is certainly not.

There are two reasons that police use DNA analysis. One is to determine whether a forensic sample matches one on file. The other is to learn more about the characteristics of an unknown perpetrator. For data-protection reasons, in most countries police databases are not allowed to store information about actual genes, but only information about DNA regions that do not code for genes. This is sufficient to allow police to match samples - a process known as genetic fingerprinting.

To learn more about what an unknown perpetrator might look like - or might not look like - requires analysis of gene-coding regions. Because crime-scene samples are not placed in databases, most countries do not regulate what can be done with them. Germany - sensitized to anything genetic by its Third Reich history of eugenics and by a cultural aversion to interfering with nature - is alone in explicitly banning the use of DNA-coding regions in criminal casework.

German police may check a sample for sex (the presence of a Y chromosome indicating male) but for little more. The proposed change to the law would allow gene-coding regions to be analysed to check for hair, skin and eye colour, and biological age. Bavaria is pushing for inclusion of biogeographical origin.

These are all analyses that have been forensically validated and that police in other countries can use in their investigations. Yet if Germany wants to continue to regulate this work, and wishes to make it useful to law enforcers, it should take great care in how it words the law. At present, for example, in naming specific traits that could be tested for, the proposal excludes other, more useful, tests that may be validated in future.

As forensic scientists know, the glamorous new genetic tools are not as straightforward as television shows such as CSI - or, in Germany, Tatort - make them out to be. Finding genes for blue or brown eyes is reliable - around 95-98\% predictive - but for hazel eyes, much less so. The continent from which a person originates can be predicted with $99.9 \%$ certainty, but the probability of determining the country roots of a person is low, whatever commercial DNA companies claim. It isn't even possible to say with any certainty whether an individual originates in Western or Eastern Europe.

And whatever CSI or Tatort would have us believe, police don't
"It will certainly be important for police to work very closely with their forensic scientists." use these techniques as often as one might think, because they have to balance their cost against their predictive value. In general, they use them as a last resort, after they have worked their way through conventional investigative methods.

Nevertheless, as technologies continue to improve and their costs fall, the methods are going to be ever more valuable to forensics. Some scientists in Germany have expressed concern that allowing such techniques, whose scientific status often masks their probabilistic nature in the eyes of the public, risks unleashing discrimination against minorities. It will certainly be important for police to work very closely with their forensic scientists, to discuss in detail what information can be realistically squeezed out of crime-scene samples, which are often rather small, and what the investigators will be able to conclude from a particular analysis.

Ironically, given the public and political landscape in Germany that surrounds the discussions of these genetic tests, experience has shown that they can also quell prejudice.

The law in the Netherlands was changed in 2003 to allow forensic DNA samples to be analysed for biogeographical origin as well as for physical characteristics such as colouring. This was because of a 1999 rape and murder for which suspicion had fallen on a local home for asylum seekers. To restore public order, a court had ordered the forensic sample to be tested - it showed that the attacker was of north European origin, not from the Middle East as most of the refugees were. The murderer was eventually found to be a local farmer.

\section{Early start}

\section{Childhood cancers are drawing the focus they deserve - a move that will yield rich rewards.}

$\mathrm{W}$ hen the England football team's mascot stepped onto the Wembley pitch before a World Cup qualifying match on Saturday, he winced and covered his ears. The roar was deafening as the crowd in London welcomed five-year-old Bradley Lowery - a fan with terminal cancer.

Over the past few months, Bradley has picked up countless fans of his own around the world. His family has raised hundreds of thousands of pounds to fund experimental treatment of his illness. The outpouring is understandable: there is no heartache like a sick child, and no greater gift than the chance to help one.

Others with the disease may also get more attention in future - from researchers, funders and the public. On the same day as Bradley's big moment, the charity Children with Cancer UK in London announced it will give $£ 1.5$ million (US $\$ 1.9$ million) towards the goal of sequencing the tumour DNA of every child with cancer in the United Kingdom. It is a worthwhile effort that could boost research - paediatric cancers are rare, and every effort should be taken to collect data when possible.

The harsh truth is that little can be done clinically with that information. The burgeoning wave of precision medicine still lags in childhood and adolescent cancers, and they are often overlooked because they are so uncommon. It is difficult to find the samples and funding for this type of research, and scientists who endeavour to do so often find themselves justifying their work by pointing out the relevance of their findings to more common, adult cancers.

As we highlight in a News Feature this week (page 608), there are positive signs of change. The US Cancer Moonshot Initiative, for one, has chosen paediatric cancers as one of its ten areas of focus - a move that some researchers hope is a sign that the plight of children with cancer is getting wider recognition.

Children could also benefit from a new focus on survivorship. The American Association for Cancer Research (AACR) meeting in Washington DC this weekend will hold sessions dedicated to understanding the long-term effects of cancer treatment. This was also listed as a focus in the Moonshot Initiative, and is an area of research that could have a particular impact on survivors of childhood cancers.

The high cure rates of some childhood cancers can be misleading: by the time these survivors reach the age of $45,80 \%$ of them will have severe or life-threatening conditions as a result of the treatments they have received. Programmes such as the St. Jude Children's Research Hospital Childhood Cancer Survivor Study, based in Memphis, Tennessee, are an important step to understanding these effects.

It is difficult to call for more money in a time of tremendous financial uncertainty - particularly in the United States, where President Donald Trump has called for an $18 \%$ funding cut to the National Institutes of Health. This will hang over the AACR meeting.

But in the face of that disquiet, it is crucial to nurture the steps that researchers and funders have taken to recognize cancers in children, adolescents and young adults. Even though paediatric cancer is rarer than adult cancer, it is important to get the message out that focusing on the disease in children yields huge dividends in terms of the years of life that can be won. 